\title{
"A QUIEN CUECE Y AMASA NO LE HURTES HOGAZA" Y OTRAS PAREMIAS EN EL QUIJOTE CERVANTINO
}

\author{
María Cándida Muñoz Medrano \\ Università degli Studi di Catania
}

\section{Resumen}

Muchos estudiosos han llamado a Don Quijote de la Mancha "refranero popular" por considerar esta obra como una fuente inexhausta de paremias populares en lengua española. Su gran corpus paremiológico es uno de los mayores monumentos folclóricos de la literatura española. Más de cuatro siglos han pasado desde que Cervantes dio vida a las paremias en su obra maestra, y con ellas el autor nos brindó el panorama de la mentalidad y la visión del mundo de esa comunidad lingüística. En este trabajo analizamos un corpus de refranes de Don Quijote ocupándonos principalmente de sus características, su estructura, la presencia que tuvieron en el Diccionario académico y su correspondencia en italiano. Con este trabajo tenemos la intención de aportar un grano de arena al estudio de la fraseología contrastiva español-italiano. Nos ocupamos tanto de las correspondencias textuales interlingüísticas como de las correspondencias en el sistema, creando las condiciones necesarias para realizar en estudios posteriores propuestas en la didáctica de las paremias a italohablantes de español como segunda lengua.

Palabras clave: Refrán, corpus paremiológico, traducción, texto, italiano.

\section{"A QUIEN CUECE Y AMASA NO LE HURTES HOGAZA" AND OTHER PAREMIAS IN DON QUIXOTE BY CERVANTES}

\begin{abstract}
Many scholars consider Don Quixote a popular collection of paremias (proverbs) in Spanish. This wide paremiological corpus is one of the greatest folkloric monuments of Spanish literature. More than four centuries have passed since Cervantes created the paremias in his masterpiece, and through them the author has given us a framework of the mindset and the worldview of the linguistic community he belonged to.

In this paper we will analyze a corpus of paremias from Don Quixote dealing mainly with their characteristics, their structure, their presence in the Academic Dictionary
\end{abstract}


and their translation correspondent in Italian. With this work we intend to contribute to the study of the contrastive Spanish-Italian phraseology. On the one hand, we deal with interlinguistic and textual correspondences and, on the other hand, we study the correspondences within the system. We are consequently creating the necessary conditions to foster the didactics of phraseology between Spanish and Italian in subsequent studies.

Keywords: Proverb, paremiological corpus, translation, text, Italian language.

\section{Introducción}

Muchos estudiosos han llamado a Don Quijote de la Mancha "refranero popular" por considerar esta obra como una fuente inexhausta de paremias populares en lengua española. Su gran corpus paremiológico es uno de los mayores monumentos folclóricos de la literatura española y, ante todo, ha llamado la atención el número de paremias que hacen aparición en la obra. Sbarbi (1922), autor del Refranero general español del siglo xix, afirma que ascienden a mil, excluyendo las variantes y las repeticiones, mientras que otros investigadores como Dos Santos (2000) reducen sustancialmente ese número; Colombi (1989) ofrece 171 paremias; Jesús Cantera, junto con Julia y Manuel Sevilla (2005), afirman que hay 81 paremias en la primera parte y 307 en la segunda, aunque estas cifras sin duda incluyen las muchas repeticiones y variantes (Cull, 2014: 147-161); Tarnovska (2004: 285-300) aduce que los refranes más populares y conocidos en la actualidad provenientes de Don Quijote llegan aproximadamente a 250. Son numeros los aspectos que han destacado los estudiosos de estas estructuras: Helmut Hatzfeld (1972: 72-74) hizo hincapié en la capacidad de visualización como una característica esencial de los refranes de Cervantes; para Ángel Rosenblat (1971: 35-43) caracterizan la lengua de Sancho Panza; otros autores se han dedicado a contrastar los refranes que aparecen en El Quijote con los que presentan otras obras, y este es el caso de O'Kane (1950: 360-369) y Joly (1971: 91-106), que los comparan con los de Rebelais, en el caso de la autora O'Kane, y con los de Mateo Alemán, en el caso de Monique Joly; Colombi (1989) los estudió como actos del habla. Asimismo ha suscitado interés el origen bíblico de los refranes y las fuentes derivadas del Romancero español, siendo numerosos los lingüistas y lexicógrafos que han estudiado los refranes, las sentencias y los aforismos empleados en El Quijote. Además de los autores nombrados se puede citar a Menéndez Pelayo, Amado Alonso, Elías Olmos y recientemente Francisco Calero, además de Américo Castro y una larga lista de autores prestigiosos. Suscita nuestro interés el libro de Calero (2000) Refranes, sentencias y pensamientos de Don Quijote de la Mancha y el trabajo de Amando De Miguel (2000) titulado El espíritu de Sancho Panza (El carácter español a través de los refranes). 
Más de cuatro siglos han pasado desde que Cervantes dio vida a las paremias en su obra maestra, y con ellas el autor nos brindó el panorama de la mentalidad y la visión del mundo de esa comunidad lingüística, unos refranes que matizan la conversación de la novela y van acompañando las fascinantes aventuras de Don Quijote y Sancho Panza, formando parte a su vez del lenguaje popular del escudero, que se contrapone al lenguaje culto utilizado por Alonso Quijano. Cervantes pone en boca de Sancho Panza innumerables refranes para dar a conocer los sucesos de la vida diaria, y a través de ellos hace una exaltación de la idiosincrasia de la vida de los pueblos y de su tradición folclórica:

Este mi amo, por mil señales, he visto que es un loco de atar, y aun también yo no le quedo en zaga, pues soy más mentecato que él, pues le sigo y le sirvo, si es verdadero el refrán que dice: «Dime con quién andas, decirte he quién eres", y el otro de "No con quien naces, sino con quien paces" (Don Quijote, ii-x, 616).

En efecto, como afirma Lázaro Carreter (2001: xxi), "la voz diferente de Sancho en la polifonía quijotesca" fue el "gran desafio en que ha triunfado Cervantes", caracterizando a este personaje por su manera peculiar de servirse de los refranes en el discurso. Al contacto con la sabiduría de don Quijote, Sancho llegará a tener y a defender sus propios principios y convicciones.

El autor no solamente engasta los refranes en el habla de los personajes, sino que también da consejos acerca de su empleo correcto, sus juicios y su valor, como hace en el Capítulo xliii de la Segunda Parte:

-También, Sancho, no has de mezclar en tus pláticas la muchedumbre de refranes que sueles; que, puesto que los refranes son sentencias breves, muchas veces los traes tan por los cabellos, que más parecen disparates que sentencias. -Eso Dios lo puede remediar - respondió Sancho-, porque sé más refranes que un libro, y viénenseme tantos juntos a la boca cuando hablo, que riñen por salir unos con otros, pero la lengua va arrojando los primeros que encuentra, aunque no vengan a pelo. Mas yo tendré cuenta de aquí adelante de decir los que convengan a la gravedad de mi cargo, que en casa llena presto se guisa la cena, y quien destaja no baraja, y a buen salvo está el que repica, y el dar y el tener seso ha menester. —Eso sí, Sancho! —dijo don Quijote—: jencaja, ensarta, enhila refranes, que nadie te va a la mano! ¡Castígame mi madre, y yo trómpogelas! Estoyte diciendo que escuses refranes, y en un instante has echado aquí una letanía dellos, que así cuadran con lo que vamos tratando como por los cerros de Úbeda. Mira, Sancho, no te digo yo que parece mal un refrán traído a propósito, pero cargar y ensartar refranes a troche moche hace la plática desmayada y baja (Don Quijote, ii-xliii, 872-873).

Los refranes, paremias por excelencia, son en la obra cervantina según observamos en este párrafo citado microtextos independientes y populares, 
patrimonio de los hablantes de aquella época y reconocibles por todos ellos, que los emplean espontáneamente. Cualquier investigador que se acerque al estudio de las paremias en el Quijote podría pensar que tras tantos trabajos dedicados a este tema el corpus de refranes está bastante bien delimitado, pero no es así, ya que según comprobamos, en muchas ocasiones se insertan frases hechas entre los refranes que nada tienen que ver con estas estructuras y, en todo caso, su consideración como paremias sería muy discutible. Con la publicación en 2005 de Refranes, otras paremias y fraseologismos en 'Don Quijote de la Mancha', Jesús Cantera Ortiz de Urbina, Julia Sevilla Muñozy Manuel Sevilla Muñoz lograron elaborar un corpus paremiológico bastante completo para la novela junto con su análisis, además de la recopilación de "otras unidades fraseológicas, expresiones, exclamaciones, juramentos y latinismos" (2005: 9). Entre todas las estructuras a las que Cervantes llama refranes hemos de aducir que no pueden considerarse como tales los que no se presentan lexicalizados, con autonomía sintáctica y textual, valor de verdad general y carácter anónimo (Corpas Pastor, 1997: 148; Martí Contreras, 2003: 238). Además, hay que destacar su carácter tradicional y propósito didáctico o dogmático (Corpas Pastor, 1997: 150).

En este trabajo analizamos un corpus de refranes de Don Quijote ocupándonos principalmente de sus características, su estructura, la presencia que tuvieron en el Diccionario académico y su correspondencia en italiano. Nos interesa igualmente averiguar cuál es su representatividad hoy en día en la comunidad hispanohablante. Hemos de precisar que nuestro interés es abordar estas estructuras desde una perspectiva preferentemente contrastiva, español-italiano, ya que consideramos que esta es la más eficaz en la didáctica de las paremias (Zamora Muñoz, 2004: 125-136) en el contexto universitario italohablante en que llevamos a cabo la enseñanza de la lengua española. El interés es iniciar a los discentes en la adquisición de una competencia fraseológica por lo menos pasiva, y que esta los conduzca a un mayor entendimiento de los entresijos culturales que encierran.

A la hora de establecer criterios en la elección de los refranes que constituyen nuestro corpus hemos considerado una serie de estructuras con variedad en la temática y un alto grado de representatividad dentro de la obra. Del corpus forman parte las siguientes estructuras: A quien cuece y amasa, no le hurtes hogaza, Ándeme yo caliente, y ríase la gente, Bien vengas mal, si vienes solo, Buen corazón quebranta mala ventura, Cuidados ajenos, matan al asno, De amigo a amigo, la chinche, Del dicho al hecho hay gran trecho, Dime con quién andas, decirte he quién eres, Más vale algo que no nada, Quien a buen árbol se arrima, buena sombra le cobija, Quien canta sus males espanta, Tan presto se va el cordero como el carnero, Todos los duelos con pan son buenos. No tienen 
la misma circulación por la comunidad hispanohablante todos los refranes enunciados, ni son conocidos de igual manera por parte de los hablantes de hoy, cuya competencia paremiológica ha disminuido de modo considerable con el paso del tiempo tendiendo a desaparecer los refranes de la conversación cotidiana actualmente. A modo de ejemplo, se puede decir que el refrán Ande yo caliente, ríase la gente es representativo en la comunidad lingüistica hispanohablante y su uso está convencionalizado; se rastrea principalmente en títulos de artículos de variada tipología y en titulares de secciones periodísticas:

¿Tolerancia? Ándeme yo caliente y ríase la gente

David Moraza nos deja un tratado sobre la tolerancia, ¿es buena o mala?

(El Mendolotudo, 4 de julio de 2016)

Se pretende con este título llamar la atención del lector e incitarlo a la lectura del artículo. Otros refranes de nuestro corpus con representatividad en Internet son los siguientes: Bien vengas mal, si vienes solo, Dime con quién andas, decirte he quién eres, Quien canta sus males espanta, Quien a buen árbol se arrima, buena sombra le cobija. No tienen representatividad, y se hallan en desuso en la actualidad, los siguientes refranes del corpus: A quien cuece y amasa, no le hurtes hogaza, Buen corazón quebranta mala ventura, Cuando la cabeza duele, todos los miembros duelen, Cuidados ajenos matan al asno, De amigo a amigo, la chiche, Del dicho al hecho hay gran trecho, Más vale algo que no nada, Tan presto se va el cordero como el carnero, Todos los duelos con pan son buenos.

\section{Análisis del corpus}

\subsection{La estructura}

La estructura de los refranes que forman parte de este corpus es muy variada. Independientemente de la estructura que tengan, se puede afirmar que en todos ellos los distintos significados aportados por los vocablos se integran de modo que la nueva oración logre crear un sentido y una cohesión globales, por ejemplo: Bien vengas mal, si vienes solo, Tan pronto se va el cordero como el cardero, Dime con quien vas, decirte he quién eres. El presente es el tiempo verbal predominante, un tiempo verbal neutro sin referencias deícticas (Corpas, 1997), aunque aparece también el imperativo. Detectamos algunas anomalías sintácticas como la ausencia de artículos, estructuras que no extrañamos porque nuestro conocimiento general de las paremias hace que las consideremos habituales: Buen corazón quebranta mala ventura, Cuidados ajenos matan al asno. Bosque (1999: 924) comenta que sintagmas como estos sin artículo no son arcaísmos sino "construcciones estilísticas en plena vitalidad", como queda comprobado en la invención actual de paremias con esta misma estructura. 
Hemos de destacar la fijación interna, tanto en el orden de los vocablos dentro de la oración, como en las categorias gramaticales y sus propiedades. Asimismo presentan fijación externa, entendida exclusivamente como una complejidad y estabilidad de forma gradual, demostrada por el hecho de que no todas presentan la misma estabilidad (Conca, 1990; Zamora Muñoz, 2003: 825-836). Este es el esquema sintáctico característico de los refranes del corpus:

- Oraciones simples: De amigo a amigo, la chiche; Más vale algo que no nada; Buen corazón quebranta mala ventura; Cuidados ajenos matan al asno; Del dicho al hecho hay gran trecho; Tan presto se va el cordero como el carnero; Más vale algo que no nada.

- Oraciones yuxtapuestas: Quien a buen árbol se arrima, buena sombra le cobija; Quien canta, sus males espanta; Bien Vengas mal si vienes solo.

- Oraciones coordinadas: Dime con quién andas y te diré quién eres; Ándeme yo caliente y ríase la gente.

- Oraciones subordinadas temporales: Cuando la cabeza duele, todos los miembros duelen; Tan presto se va el cordero como el carnero.

\subsection{Análisis de características}

En este apartado, en primer lugar se contextualizan los refranes en ambas lenguas y se aporta la definición que la Real Academia Española de la Lengua ha dado de estos refranes en su Diccionario. Se cotejan las distintas ediciones desde el Diccionario de Autoridades (1726-1739).

$\mathrm{El}$ análisis que efectuamos va encaminado a individualizar características fundamentales de los refranes, tales como el tema, el motivo, el sentido, las variantes léxicas, los sinónimos y las correspondencias en la lengua italiana. Una vez que se han analizado las características, nos concentramos en las correspondencias textuales de estos refranes en la traducción de la obra cervantina llevada a cabo por Alfredo Giannini. En último lugar, consideramos de capital importancia establecer cuál ha sido la tipologia de correspondencia establecida, aplicando las teorías de una serie de estudiosos que más adelante damos a conocer.

En nuestro análisis ha resultado de gran provecho distinguir entre refranes retóricos y no retóricos, es decir, los que contienen un tropo, entendido este en el sentido clásico del término como una figura en el ámbito de los lexemas, y los que no lo contienen. Los refranes retóricos y los no retóricos no presentan diferencias en la estructura, puesto que al establecerse la diferencia en el ámbito de los lexemas, la estructura base, la que está constituida en el ámbito de la organización sintáctica, permanece común a ambos, aunque sí existan diferencias (Barsanti Vigo, 2008) en cuanto al contenido. 


\subsection{El concepto de equivalencia}

En el concepto de equivalencia ${ }^{1}$ interlingüistica de los refranes hay que diferenciar entre equivalencias en el sistema y equivalencias textuales. La primera tarea está relacionada con la fraseología contrastiva, que compara fraseologismos de dos o más lenguas para determinar las semejanzas y las diferencias existentes entre ellos, mientras que la equivalencia en el nivel del texto se halla relacionada con un fenómeno eminentemente textual, y se adscribe a la traductología. La traducción de refranes es una labor complicada ya que estos textos están marcados por la sabiduría popular, y esta labor de traducción implica asimismo la traducción de la cultura. Como afirman los estudiosos el concepto de la equivalencia es uno de los más ambiguos en los estudios sobre traducción y, por consiguiente, se presta a multitud de interpretaciones (Hurtado, 2007: 205).

Dentro de la dirección encaminada a establecer equivalencias textuales, Stella Tagni (1988) abogaba por las siguientes estrategias de traducción:

1. Mantener la expresión en la forma original, que sería una transcripción.

2. Mantener la expresión en la forma original con nota explicativa añadida, tarea que también sería una transcripción pero con la nota explicativa, cuya utilización dependería del conocimiento que tiene el público.

3. La traducción literal, tarea que la autora denomina léxico-pragmática, que debería ir acompañada de nota en ausencia de un equivalente pragmático que aclare las diferencias entre las culturas.

4. Explicitar la expresión en el texto.

5. Emplear un equivalente pragmático.

Estas consideraciones las adapta la autora y las circunscribe a la equivalencia entre proverbios años más tarde (Tagnin, 2005: 80-82): proverbios iguales en las dos lenguas, a los que nosotros a partir de Wotjiak y Corpas les atribuimos una equivalencia total siempre que tengan la misma estructura y el mismo contenido significativo en ambas lenguas; proverbios con el mismo sentido en las dos lenguas y formas solamente semejantes, que serian equivalentes solo parcialmente; proverbios con el mismo significado, pero con formas diferentes en las dos lenguas, casi con equivalencia parcial; y por último proverbios sin correspondencia en italiano.

Francisco Díez (1995) aduce que cuando no se produce equivalencia intercultural se intensifica la complejidad formal de los proverbios, pero esta

${ }^{1}$ Sevilla Muñoz y González Rodríguez (1994-1995: 171-182) y Zuluaga Ospina (2001: 68) usan el término correspondencia para las equivalencias establecidas, término que preferimos y a partir de ahora vamos a utilizar.

AEF, vol. XL, 2017, 117-134 
situación como vamos a observar a continuación escasamente se produce en el caso de los pares lingüísticos español-italiano en la obra cervantina, por lo que no podemos hablar de intraducibles o intransferibles, o lo que es lo mismo de no equivalencia como hace el autor. Postigo Aldeamil (2000) propone un procedimiento de sistematización para analizar la traducción de proverbios, clasificándolos según su correspondencia literal o conceptual con el proverbio utilizado. A partir de esta autora consideramos que se pueden tener en cuenta las siguientes posibilidades a la hora de establecer las correspondencias:

- Proverbios existentes en las dos lenguas: la mayoría de los refranes que forman parte de nuestro corpus se exponen a una correspondencia literal total, o bien parcial o bien a una correspondencia equivalente. Los refranes que presentan una correspondencia literal total son equivalentes en forma y contenido y conservan en italiano las equivalencias semánticas y estilísticas. La correspondencia literal parcial ocurre cuando el refrán español tiene en italiano una equivalencia formal en la estructura y en el contenido, aunque presente alguna alteración en el léxico. Este tipo de correspondencia literal, total o parcial, es frecuente entre el españoly el italiano.

- Refranes existentes en una sola lengua: en este caso el traductor puede optar por una traducción literal, por una paráfrasis. La correspondencia equivalente sería la correspondencia del sentido del refrán en español en términos diferentes en italiano, que podemos llamar paráfrasis.

- Por último, la supresión u omisión de proverbios del original.

Las traducciones que aparecen en la versión italiana de Don Quijote de la Mancha de los refranes de nuestro corpus son las siguientes:

- Bien vengas mal, si vienes solo= Ben venga, o male, se tu vieni solo.

- Más vale algo que no nada = Meglio poco che nulla .

- De amigo a amigo la chinche $=$ Dall'amico ti riguarda .

- Dime con quién andas, decirte he quién eres $=$ Dimmi con chi vai e ti dirò chi sei.

- Aquien cuecey amasa, nole jurtes hogaza = A chi fa il pane e staccia non gli si ruba la focaccia.

- Quien a buen árbol se arrima, buena sombra le cobija = Chi a buon albero s'appoggia, buon ombra lo ricuopre.

- Cuidados ajenos matan al asno = S'impaccia de' mali altrui, di tre gliene tocca dui.

- Ándeme yo caliente y ríase la gente $=$ Ch'io stia caldo e ben turato, e di me rida chi vuole.

- Quien canta sus males $=$ Chi canta scaccia malinconia. 
De entre los escasos estudios teóricos que ofrecen una reflexión acerca de la traducción de los enunciados sentenciosos destacan los realizados por Sevilla Muñoz (2011) y Sevilla Muñoz y Sevilla Muñoz (2000, 2004, 2005a, 2005b). Hemos de aducir a partir de estos estudios que el proceso de traducción se complica a medida que aumentan las dificultades textuales, terminológicas, conceptuales, gramaticales y semánticas; también Wotjak (1983), Corpas Pastor (1997) y Mellado Blanco (2000) postulan en sus trabajos la existencia de una escala gradual de equivalencias que oscila entre un grado total o pleno y un grado nulo. Asimismo la pérdida de competencia paremiológica por parte de los traductores y la escasez de diccionarios especializados bilingües de fácil acceso dificultarían este proceso. Estos estudiosos, que sustituyen el término traducción por el término correspondencia, distinguen entre correspondencia literal y correspondencia conceptual. La correspondencia literal es total y parcial, mientras que cuando la estructura se traduce por otra del italiano con el mismo contenido significativo, la correspondencia es conceptual.

\section{El corpus}

Por cuestiones de espacio se van a analizar solo diez refranes de los que componen el corpus.

\subsection{Bien vengas mal, si vienes solo}

[...] a cada paso pienso que debajo de los pies de improviso se ha de abrir otra sima más profunda que la otra, que acabe de tragarme. iBien vengas mal, si vienes solo! (Don Quijote, ii-lv, pág. 291).

[...] a ogni passo penso che sotto i piedi, all'improvviso, mi si debba aprire un nuovo precipizio ancora più profondo, che finisca d'inghiottirmi. Ben venga, o male, se tu vieni solo (Don Chisciotte, ii-lv, pág. 1183)².

Este refrán aparece en el Diccionario de la Real Academia en su edición de 1726: "Proverbio, que advierte lo que tan repetidamente manifiesta la experiencia, que los males por lo regular vienen encadenados y juntos, y los bienes sueltos y esparcidos". El refrán muestra la esperanza de que los males y las desgracias no vengan unos detrás de otros. Así, Sancho espera que la desgracia de caerse con su jumento en una cima sea su único mal en ese momento. Tipológicamente el refrán es bimembre y retórico, el "mal" aparece personificado, un elemento abstracto que se concretiza. El refrán funciona como elemento evaluativo dentro del discurso; Cervantes lo incorpora al discurso sin efectuar ningún tipo de modificación.

${ }^{2}$ Los fragmentos en italiano proceden de la edición Don Chisciotte della Mancia (2007) con traducción y notas de A. Giannini. 
El tema que expresa este refrán es la desgracia, el motivo o palabra clave es el mal. Son válidas todas las características atribuidas al refrán español para el refrán italiano: se trata igualmente de un refrán retórico, es asimismo bimembre y su función es la misma en la versión italiana. La diferencia en cuanto a la estructura sintáctica queda patente por la interposición del vocativo o male en el texto italiano. La correspondencia es por lo tanto literal casi total entre ambas estructuras. Otras variantes o sinónimos son: Le disgrazie non vengono mai sole, con alta frecuencia de uso, A una disgrazia ne segue un' altra; Le sventure sono come gli sternuti: di rado ne avviene uno solo; Le sventure sono come le ciliegie: vengono a due a due; Un malanno/male tira l'altro.

\subsection{Más vale algo que no nada}

[...] que yo la aderezaré en el primer lugar donde haya herrero, y de suerte que no le haga ventaja, ni aun le llegue, la que hizo y forjó el dios de las herrerías para el dios de las batallas; $y$, en este entretanto, la traeré como pudiere, que más vale algo que no nada; cuanto más, que bien será bastante para defenderme de alguna pedrada (Don Quijote, i-xxi, pág. 190).

Nel primo borgo dove ci sia un fabbro io la risistemerò in modo che non la sorpassi e neanche le si approssimi quella che fece e foggiò il dio delle fucine per il dio delle battaglie, e frattanto la porterò come potrò; meglio poco che nulla; per lo meno mi basterà per ripararmi da qualche sassata. (Don Chisciotte, i-xxi, pág. 231).

Este refrán aconseja no despreciar ninguna cosa que se ofrezca, se encontraba ya en la tradición latina. En el Diccionario académico de 1934, cuando aparece por primera vez, se define como "Modo de hablar con que se advierte, que no se deben despreciar las cosas por mui pequeñas ù de poca entidad". Cervantes lo pone en boca de Don Quijote cuando el caballero explica a Sancho lo que hará con el encantado yelmo: lo utilizará en las condiciones en que se encuentra hasta que vaya a casa de un herrero y se lo componga. Más vale algo que no nada en este contexto significa que prefiere tener el yelmo aunque sea transmutado en vacía que no tenerlo. El tema que expresa el refrán es el conformismo. Se trata de un refrán no retórico. Se puede decir asimismo que no hay motivo y que el tema del refrán no está indicado por ningún vocablo presente en la estructura; la contrariedad que se expresa por medio de los indefinidos algo/nada funciona como elemento evaluativo. Asimismo, esa contrariedad también se expresa en la versión italiana de la paremia a través de los indefinidos poco/niente. Son válidas todas las características atribuidas al refrán español para el refrán italiano: se trata igualmente de un refrán no retórico y unimembre, su función es la misma en la versión italiana. 


\subsection{De amigo a amigo, la chinche}

Digo que dicen que dejó el autor escrito que los había comparado en la amistad a la que tuvieron Niso y Eurialo, y Pílades y Orestes; y si esto es así, se podía echar de ver, para universal admiración, cuán firme debió ser la amistad destos dos pacíficos animales, y para confusión de los hombres, que tan mal saben guardarse amistad los unos a los otros. Por esto se dijo: «No hay amigo para amigo: / las cañas se vuelven lanzas"; y el otro que cantó: De amigo a amigo la chinche (Don Quijote, ii-xii, pág. 633).

Si dice, per di più, che l'autore lasciò scritto di avere paragonata la loro amicizia a quella che fu tra Niso ed Eurialo e tra Pilade e Oreste; dal che, se è vero, si poteva conoscere, ad ammirazione di tutti, quanto salda doveva essere l'amicizia di questi due pacifici animali, a obbrobrio degli uomini i quali così malamente sanno serbare amicizia fra loro. Perciò fu detto: «Non ha amico più l'amico: / delle canne si fan lancen; e qualcun altro cantò: Dall'amico ti riguarda (Don Chisciotte, ii-xii, pág. 770).

Este refrán representa las ingratitudes que a veces llegan de quienes se llaman amigos. Alude a quienes hieren en lo más delicado a las personas que le han otorgado su confianza. Por eso, se recomienda no confiar demasiado en los que se venden por amigos. Este refrán no lo incluyen las ediciones del Diccionario académico de 1726 ni de 1734. Aparece una variante con el mismo significado en la de 1893: De amigo á amigo ó de compadreá compadre chinche en el ojo. "Ref. Que enseña a no confiar demasiado en los que se venden por amigos".

El tema de este refrán es la ingratitud, y el motivo está representado por el vocablo chinche, que tiene una serie de connotaciones para el lector: este insecto segrega una sustancia maloliente, taladra la piel con picaduras irritantes, y así el lexema chinche quiere implicar o connotar a ese mal amigo cuya ingratitud puede ser punzante y molesta. Sintácticamente la estructura se caracteriza por la ausencia de verbos. El traductor no elige un refrán para su versión (Dall'amico, ti riguarda), algunos equivalentes en italiano son: Il miglior amico, la miglior sassata / dal miglior amico la peggior sassata, Il miglior amico tuo ti tradisce per primo.

\subsection{Dime con quién andas, decirte he quién eres}

Este mi amo, por mil señales, hevisto que es un loco de atar, y aun también yo no le quedo en zaga, pues soy más mentecato que él, pues le sigo y le sirvo, si es verdadero el refrán que dice: Dime con quién andas, decirte he quién eres, y el otro de No con quien naces, sino con quien paces (Don Quijote, ii-x, pág. 616).

Questo mio padrone ho visto da mille prove che è un matto da legare, e anche io, del resto, non gli rimango punto indietro, perché, se è vero il proverbio che dice "dimmi con chi vai e ti dirò chi sei" e l'altro "non donde nasci, ma donde pasci", sono più matto di lui perché lo seguo e lo servo (Don Chisciotte, ii-x, pág. 752). 
Este refrán indica que cada persona suele buscarse amistades y compañias semejantes a sí mismo. Resultan fácilmente identificables los gustos y forma de ser de alguien en función del tipo de personas con las que se relaciona. Asimismo, se usa para indicar la fuerte influencia que las personas pueden tener en nosotros. En el Diccionario académico de 1780, primera vez que aparece documentado el refrán, se dice que "[...] advierte lo mucho que influyen en las costumbres las buenas ó malas compañias". Aparece en las ediciones de 1817 y de 1884 con la misma definición, en las ediciones posteriores no aparece. El tema de este refrán es la influencia de las amistades, y el motivo no se puede deducir a partir de ninguno de los vocablos que forman parte de esta paremia. Sinónimos de este refrán son: Con cual te hallares, con tales te haré. No con quien naces, sino con quien paces. El traductor ha optado por la correspondencia literal total con el refrán que ya existe en italiano Dimmi con chi vai e ti dirò chi sei.

\subsection{A quien cuece y amasa, no le hurtes hogaza}

Eso de gobernarlos bien — respondió Sancho— no hay para qué encargármelo, porque yo soy caritativo de ío y tengo compasión de los pobres; y $a$ quien cuece y amasa, no le jurtes hogaza; y para mi santiguada que no me han de echar dado falso; soy perro viejo, y entiendo tus, tus, y sé despabilarme a sus tiempos, y no consiento que me anden musarañas ante los ojos, porque sé dónde me aprieta el zapato [...] (Don Quijote, ii-xxiii, pág. 728).

Quanto a governarli bene -rispose Sancio- non occorre raccomandarmelo, perché io sono caritatevole di mio ed ho compassione dei poveri, e $a$ chi fa il pane e staccia non gli si ruba la focaccia e, per la santa croce di Cristo, a me non me li scambiano i dadi; son volpe vecchia e formicon di sorbo, e so risvegliarmi al momento buono, e non mi lascio passare nuvoline davanti agli occhi, perché so bene dove mi stringe la scarpa [...] (Don Chisciotte, iixxxiii, pág. 984).

Este refrán aparece por vez primera en la edición del Diccionario académico de $1817 \mathrm{Y}$ "[...] advierte que al que está experimentado y práctico en alguna cosa no se le puede engañar en ella con facilidad". Con la misma definición aparece también el refrán en las ediciones de 1884 y de 1925. Después de esa fecha desaparece. Se trata tipológicamente de un refrán bimembre y retórico, el tema es el engaño, y el motivo queda representado por el vocablo "hogaza", que connota el tema del refrán. El sentido de este refrán es que a las personas experimentadas en la vida es difícil engañarlas.

Hogaza, palabra clave de este refrán, se define en el Diccionario académico de 1780 como "[...] pan grande y que pesa mas de dos libras, como son los que hacen en los lugares, porque no se cuece todos los dias. Antiguamente se llamaba asi el pan de salvado, ó harina mal cernida, que hacian para la gente del campon. Procede de focacia, vocablo latino. Se consumía en el campo 
y los textos literarios la citan con frecuencia. Sancho utiliza este refrán en un diálogo con la Duquesa sobre la forma en que gobernará su ínsula. El escudero quiere decir que él sabrá cómo gobernarla bien.

El refrán funciona como argumento evaluativo dentro del discurso, se utiliza para ejemplificar y emitir un juicio de valor, consigue el autor con ello que lo expresado en la segunda parte o estructura del refrán, "no le hurtes hogaza", sea una ampliación a lo expresado inmediatamente antes. Cervantes incorpora este refrán al discurso sin que sufra ningún tipo de modificación. Por lo que respecta a la traducción, el traductor lo incorpora sin variaciones sustanciales, se trata también de un refrán retórico y bimembre y con la misma función en el texto en italiano.

Existe una variante léxica de este refrán con la primera parte idéntica: a quien cuece y amasa, de todo le pasa. La traducción que se da de este refrán mantiene una correspondencia literal casi total con el refrán español, presenta una equivalencia en la estructura y en el contenido, aunque cambie el léxico usado: A chi fa il pane e staccia non gli si ruba la focaccia.

\subsection{Quien a buen árbol se arrima, buena sombra le cobija}

-Sí soy —respondió Sancho-; y soy quien la merece tan bien como otro cualquiera; soy quien júntate a los buenos y serás uno dellos, y soy yo de aquellos no con quien naces, sino con quien paces, y de los quien a buen árbol se arrima, buena sombra le cobija (Don Quijote, ii-xxxii, pág. 794).

- Sì, son io -rispose Sancio-; e son uno che la merita quanto qualsiasi altro; sono uno che accompàgnati coi buoni e sarai uno di loro; io sono di quelli che non donde sei, ma donde pasci; e di quelli che chi a buon albero s'appoggia, buon ombra lo ricuopre (Don Chisciotte, ii-xxxii, pág. 965).

Este refrán, que había comenzado teniendo un sentido político, se empleaba en la sociedad burguesa del siglo xv para indicar el provecho que se podía sacar de las asociaciones. También fue frecuente en los refraneros clásicos. En la edición del Diccionario académico de 1780 aparece con el siguiente significado: "ref. Que da à entender la fortuna que logra el que tiene protección poderosa". Con el mismo sentido aparece en las siguientes ediciones de 1817, 1884 y 1925. El tema de este refrán es la protección y el motivo está representado por la palabra 'árbol', que tiene implicaciones o connotaciones para el lector — protección árbol-y es un refrán retórico con una estructura bimembre y yuxtapuesta. En la versión que hace el traductor a italiano son válidas todas las características atribuidas al refrán español: se trata de un refrán retórico, con la misma palabra clave o motivo en italiano, albero, e idéntica función. Son sinónimos de ambos refranes los siguientes: Quien tiene padrino, se bautiza, Chi ha buoni padrini, ha buone ciambelle. 


\subsection{Cuidados ajenos matan al asno}

-Por eso-respondió el delBosque-dicen que la codicia rompe el saco; y si va a tratar dellos, no hay otro mayor en el mundo que mi amo, porque es de aquellos que dicen: Cuidados ajenos matan al asno; pues, porque cobre otro caballero el juicio que ha perdido, se hace el loco, y anda buscando lo que no sé sidespués de halladole ha de salir a los hocicos (Don Quijote, ii-xiii, pág. 641).

-Perciò - riprese quel dal Bosco- si dice che il troppo bene sfonda la cassetta. Che se poi s'ha a dire di cavalieri pazzi, non ce n'è al mondo uno più pazzo del mio, essendo di quelli di cui si dice: chi s'impaccia de' mali altrui, di tre gliene tocca dui giacché, pur di vedere recuperare il senno a un altro cavaliere che l'ha smarrito, si fa matto lui e s'è messo alla ricerca di cosa che, quando l'avrà trovata, non so mica se non abbia a farlo ingrugnire (Don Chisciotte, ii-xiii, pág. 780).

Este refrán lo define el Diccionario académico de 1780 como «ref. que enseña que es de necios tomar cuidado en lo que no les importa". Con el mismo significado aparece en las ediciones de 1817 y de 1884 , mientras que en la edición de 1925 se enuncia como "ref. que censura a los entremetidos". Se trata de un refrán retórico, el motivo está representado por el vocablo asno. Es un refrán retórico bimembre. Es sinónimo de este refrán: Los cuidados del vecino, sentirlos con taza de tino, Chi lascia il cavallo in cura ad altri presto andrà a piedi. Presenta una correspondencia equivalente en el texto: chi s'impaccia de' mali altrui, di tre gliene tocca dui.

\section{8. Ándemeyo caliente, y ríase la gente}

Mirad la tal por cual, hija del hartode ajos, y cómo va sentada y tendida en el coche, como si fuera una papesa!» Pero pisen ellos los lodos, y ándeme yo en mi coche, levantados los pies del suelo "iMal año y mal mes para cuantos murmuradores hay en el mundo, y ándeme yo caliente, y ríase la gente! ¿Digo bien, madre mía? (Don Quijote, ii-1, pág. 945).

Guarda quella cirimbràccola, figlia di quel villano che appesta d'aglio, come se ne sta comodamente sdraiata in carrozza, quasi che fosse una papessa!» Ma che calpiccino loro la mota e io me ne vada nella mia carrozza, con i piedi ben alti da terra. "Il mal anno ed il mal mese a quanti mormorano nel mondo: ch'ío stia caldo e ben turato, e di me rida chi vuole. Dico bene, madre mia? (Don Chisciotte, ii-xxii, págs. 1139-1140).

Aparece por vez primera en el Diccionario académico de 1780: «ref. que denota que se debe preferir la comodidad á la opinion agena." Más tarde aparece en la edición de 1817 en la entrada 'andar' con el mismo significado que en la edición anterior. Es un refrán retórico, y bimembre, cuyo tema es las preferencias, se debe preferir la comodidad de uno mismo por encima de los convencionalismos sociales. Presenta una variante léxica: ande yo caliente y ríase la gente y un sinónimo: Diga mi vecina y tenga mi costal de harina. En el 
texto el traductor aporta una correspondencia nula. Existe en italiano una paremia sinónima del refrán español: Non ti curar di lor, ma guarda e passa.

\subsection{Quien canta sus males espanta}

-Pues, ¿Cómo - repitió don Quijote-, por músicos y cantores van también a galeras? — Sí, señor — respondió el galeote-, que no hay peor cosa que cantar en el ansia. - Antes, he yo oído decir — dijo don Quijote- que quien canta sus males espanta (Don Quijote, i-xxii, pág. 201).

- Ma come? - replicò don Chisciotte- Perché maestri di musica e canto si va alle galere? - Sissignore — rispose il galeotto-; non c'èla peggio che "cantare" nella "margherita". - Anzi io ho sentito dire - disse don Chisciotte-, che chi canta scaccia malinconia (Don Chisciotte, i-xxii, pág. 245).

Aparece por primera vez en la edición del Diccionario académico de 1780 como "ref. que enseña que para el alivio de los males, ó aflicciones conviene buscar alguna diversión", y queda suprimido en las ediciones de 1817y 1884 para volver a aparecer en la edición de 1925: «ref. que prueba cuánto ciega el amor propio, que nos impide conocer nuestros defectos." Es un refrán retórico y bimembre. El tema es el buen humor y la positividad ante cualquier circunstancia adversa. La correspondencia en la versión italiana es nula. Existe un sinónimo del refrán español: Canta che ti passa.

\subsection{Buen corazón quebranta mala ventura}

-Yo iréy volveré presto — dijo Sancho-;y ensanche vuestra merced, señor mío, ese corazoncillo, que le debe de tener agora no mayor que una avellana, y considere que se suele decir que buen corazón quebranta mala ventura, y que donde no hay tocinos, no hay estacas; $\mathrm{y}$ también se dice: donde no piensa, salta la liebre (Don Quijote, ii-x, pág. 615).

-Andrò e presto tornerò — disse Sancio—; e voglia vossignoria, padron mio, allargare cotesto cuoricino che ora lo deve avere non più grosso di una nocciuola, e rifletta che si suol dire che cuor forte rompe cattiva sorte e che altre cose in presenza ed altre in apparenza; e si dice anche vien più presto quel che non si spera (Don Chisciotte, ii-x, pág. 750).

Aconseja este refrán tener buen ánimo porque con él se vencen las dificultades y se hacen más llevaderas las circunstancias adversas. Aparece por vez primera en el Diccionario académico de 1817: "ref. que exhorte á no descaecer en los infortunios, porque con el ánimo se hacen más tolerables, y aun suele enmendarse ó evitarse la desgracia». Con el mismo significado vuelve a aparecer hasta las ediciones de 1884 y de 1925. El tema del refrán es la positividad ante las adversidades, y el sentido que destacamos es que la fuerza y el ánimo de espíritu hacen más llevaderos los momentos difíciles y adversos. Presenta una correspondencia textual literal parcial en italiano: Cuor forte rompe cattiva sorte. 
«Aquien cueceyamasa no le hurtes hogaza»...

\section{Conclusión}

Tras realizar una breve introducción con la que queremos contextualizar aspectos de variada tipología relacionados con el universo paremiológico creado por Cervantes en su obra maestra, se aborda el estudio de un reducido corpus de refranes - si los comparamos en número con los que aparecen en la obra - de temática variada, que el autor casi siempre pone en boca de Sancho Panza. Los objetivos son los de estudiar cada uno de estos refranes analizando sus características por lo que atañe a la estructura sintáctica, a su significado desde que aparecen por vez primera en el Diccionario académico, así como sus sinónimos y variantes y su correspondencia en italiano. Con este trabajo tenemos la intención de aportar un grano de arena al estudio de la paremiología contrastiva español-italiano. Nos ocupamos tanto de las correspondencias textuales interlingüísticas, al hacer una comparación contrastiva, como de las correspondencias en el sistema, creando las condiciones necesarias para realizar en estudios posteriores propuestas en la didáctica de las paremias a italohablantes de español como segunda lengua.

\section{Bibliografia}

Barsanti Vigo, M.J. (2008): "Los refranes en El Quijote: estudio lingüístico y literario". En Sevilla Muñoz, J. et al. (eds.): Los refranes y el Quijote. Atenas, Ta kalós keímena, págs. 49-72.

Bosque, I. y Demonte, V. (1999): Gramática descriptiva de la lengua española. Madrid, Espasa-Calpe, vol. ii.

Calero, F. (2000): Refranes, sentencias y pensamientos recogidos en la inmortal obra de Cervantes Don Quijote de la Mancha. Madrid, Guillermo Blazques.

Cervantes Saavedra, M. de (2007): Don Chisciotte della Mancia. Milano, Bur.

Colombi, M.C. (1989): Los refranes en el Quijote: texto y contexto. Potomac, Scripta Humanistica.

Conca, M. (1990): Paremiología. Valencia, Universitat de València.

Corpas Pastor, G. (1997): Manual de fraseología española. Madrid, Gredos.

Cull, J.T. (2014): «Nunca mucho costó poco. Una vez más sobre las paremias del Quijotem. Paremia, 23, págs. 147-161.

De Miguel, A. (2000): El espíritu de Sancho Panza (El carácter español a través de los refranes). Madrid, Espasa Calpe.

Díez, F.G. (1995): «Idiomaticidad y traducción». Cuadernos de Filología Inglesa, 4, págs. 27-42.

Dos Santos, G.: Los refranes en Don Quijote de la Mancha. Universidade Federal de Santa Catarina (en linea: <http://www.cce.ufsc.br/ humble/Glaucia.htm> [consulta: 10 de octubre de 2016]).

Hatzfeld, H. (1972): «El Quijote como obra de arte del lenguaje». Revista de Filología Española, anejo 83, págs. 72-74. 
Hurtado Albir, A. (2007): Traducción y traductología: introducción a la traductología. Madrid, Cátedra.

Joly, M. (1971): “Aspectos del refrán en Mateo Alemán y Cervantes». Nueva Revista de Filología Hispánica, 20, págs. 91-106.

Lázaro Carreter, F. (2001): «Estudio preliminar: Las Voces del Quijote». En Cervantes, Miguel de (2015): Don Quijote de La Mancha. F. Rico (ed.). Barcelona, Alfaguara.

Martí Contreras, J. (2003): "Genio y figura hasta la sepultura” o del estudio diacrónico de las paremias en Don Quijote de la Mancha". Res Diachronicae, 2, págs. 238-243.

Mellado Blanco, C. (2000): «Formas estereotipadas de realización no verbal en alemán y español: los cinegramas desde un enfoque contrastivo histórico". En Corpas Pastor, G. (ed.): Las lenguas de Europa: estudios de fraseología, fraseografía y traducción. Interlingua, 12. Granada, Comares, págs. 389-410.

O’Kane, E. (1950): "The Proverb: Rabelais and Cervantes». Comparative Literature, 2, págs. 360-369.

Postigo Aldeamil, M.J. (2000): «Las paremias del Quijote y la traducción de Aquilino Ribeiro". En Carrasco González, J.M. et al. (eds.): Actas del Congreso Internacional de Historia y Cultura en la Frontera. Primer Encuentro de Lusitanistas Españoles (Cáceres, 10, 11 y 12 de noviembre de 1999). Cáceres, Universidad de Extremadura, vol. 2, págs. 999-1014.

Rosenblat, Á. (1971): La lengua del Quijote. Madrid, Gredos.

Sbarbi, J.M. (1922): Diccionario de refranes, adagios, proverbios, modismos, locuciones y frases proverbiales de la lengua española: recogidos y glosados por el autor. Madrid, Sucesores de Hernando.

Sevilla Muñoz, J. (1988): Hacia una aproximación conceptual de las paremias francesas y españolas. Madrid, Editorial Complutense.

- (1993): "Las paremias españolas: clasificación, definición y correspondencia francesa». Paremia, 2, págs. 15-20.

- (2008): "Las categorías paremiológicas en el Quijote». En Sevilla Muñoz, J. et al. (eds.): Los refranes y el Quijote. Atenas, Ta kalós keímena, págs. 249-264.

- (2011): "La técnica hiperonímica en la traducción de refranes y frases proverbiales». El Trujamán. Revista diaria de traducción (en línea: < http://cvc.cervantes. es/trujaman/anteriores/septiembre_13/11092013.htm> [consulta: 15 de abril de 2017]).

Sevilla Muñoz, J. y Cantera Ortiz Urbina, J. (2001): 1001 refranes españoles con su correspondencia en ocho lenguas. Madrid, Ediciones Internacionales Universitarias.

- (2002): Pocas palabras bastan. Vida e interculturalidad del refrán. Salamanca, Centro de Cultura Tradicional.

Sevilla Muñoz, J. y González Rodríguez, A. (1994-1995): «La traducción y la didáctica de las expresiones idiomáticas (francés-español)». Équivalences, 24.2 y 25.1-2, págs. 171-182. 
Sevilla Muñoz, J. y Sevilla Muñoz, M. (2000): "Técnicas de la 'traducción paremiológica' (francés-español)». Proverbium, 17, págs. 369-386.

- (2004): "La técnica actancial en la traducción de refranes y frases proverbiales". El Trujamán. Revista diaria de traducción (en linea: <http://cvc.cervantes.es/trujaman/anteriores/noviembre_04/08112004.htm>).

- (2005a): "La técnica sinonímica en la traducción de refranes y frases proverbiales». El Trujamán (en línea: <http://www.cvc.cervantes.es/trujaman> [consulta: 15 de abril de 2017]).

- (2005b): «La aplicación de las técnicas de la ‘traducción paremiológica' a las paremias populares relativas al vocablo pez en español, inglés y francés". Revista de literaturas populares, 2, págs. 349-368.

Sevilla Muñoz, J. y Zurdo Ruiz-Ayúcar, M.I.T. (dirs.) (2009): Refranero multilingüe. Madrid. Instituto Cervantes (en línea: <http://cvc.cervantes.es/lengua/ refranero/> [consulta: 15 de abril de 2017]).

Tagnin, S.E. (2005): Ojeito que a gente diz: expressões convencioais e idiomáticas. São Paulo, Disal.

Tarnovska, O. (2005): "Sobre los refranes en El Quijote». Didáctica (Lengua y Literatura), 17, págs. 285-300.

Wotjak, G. (1983): «En torno a la traducción de unidades fraseológicas (con ejemplos tomados del español y el alemán)". Linguistische Arbeitsberichte, 40, págs. 56-80.

Zamora Muñoz, P. (2003): "Esquemas sintácticos fraseológicos pragmáticos». En Almela Pérez, R. et al. (coords.): Homenaje al profesor Estanislao Ramón Trives. Murcia, Universidad de Murcia, vol. 2, págs. 825-836.

- (2004): «La fraseología italiana y su enseñanza-aprendizaje». Paremia, 13, págs. 125-136.

Zuluaga Ospina, A. (2000-2001): "Análisis y traducción de unidades desautomatizadas». Phin-Philologie im Netzt, 16, págs. 67-83. 
